\title{
Ten-Year Performance of Shell-Treated Wooden Deck ${ }^{1}$
}

\author{
Jong Bum RA(D) ${ }^{2, \dagger}$
}

\begin{abstract}
The performance of a wooden deck made of refractory materials that have difficulties in achieving target penetrations as stipulated in the specification and quality standards for treated wood in Korea, was assessed via a case study in this research. A wooden deck built in Jinju in 2009 was selected for this study because of its fabrication method using pressure and treated refractory materials. The penetration and retention analysis did not satisfy the domestic standard for treated wood. Inspection of the deck in 2019 revealed that the deck had been attacked by decay fungi. Cap rails showed much deeper and wider checking on their surface compared with the top and base rails, resulting in a severe fungal attack. The decking boards exhibited severe fungal decay primarily in the end parts. However, the rails and balusters without checks and posts were virtually free of fungal attack irrespective of the preservative penetration measures. Copper content in the soil $5 \mathrm{~cm}$ away from the deck was less than $150 \mathrm{mg} / \mathrm{kg}$, implying that copper movement in the soil was very limited. These results suggest that the inhibition of surface propagation and the protection of end surfaces are essential factors in increasing the longevity of treated wooden decks; further, the results also showed that the deck was within an acceptable range from the point of copper contamination.
\end{abstract}

Keywords: copper contamination, refractory species, surface checks, wooden deck

\section{INTRODUCTION}

The majority of the wooden decks in Korea are fabricated using wood that has been pressure-treated with a water-borne preservative system such as Alkaline Copper Quat (ACQ). The well-treated wood should provide decades of protection from biological deterioration. However, the service life of the wooden deck in Korea tends to be much shorter than generally thought, which may be explained by the inappropriate use of refractory species such as larch, hemlock, Douglas-fir, and European Redwood. Currently, the most popular species preferred by the industries is European Redwood that has been imported mainly from Northern Europe and Russia.

The treatability class of the heartwood of European Redwood is between 3 to 4 (EN 350-2, 1994). The wood classified as class 3 mean that the lateral penetration after pressure treatment is limited in more than $3 \mathrm{~mm}$ to $6 \mathrm{~mm}$, and class 4 distinction means that it is virtually impervious to treatment: little preservative absorbed even after pressure treatment. Thus, it is difficult for the heartwood to achieve a penetration requirement of $8 \mathrm{~mm}$ in the specification and quality standard for preservative-treated wood at the above-

${ }^{1}$ Date Received July 10, 2019, Date Accepted October 16, 2019

2 Department of Interior Materials Engineering, Gyeongnam National University for Science and Technology, 33 Dongjin-Ro, Jinju 52725, Republic of Korea

† Corresponding author: Jong Bum RA (e-mail: jb@gntech.ac.kr, ORCID: 0000-0002-5015-7319) 
ground conditions without incising (Choi et al., 2011; Kang et al., 1995; NIFoS, 2018; Ra et al., 2017).

By nature, refractory species limit the lateral movement of water across the wood grain from the surface when rain directly contact with the wood. It is a good advantage because the species can provide the sort of protection from water absorption that causes checking, and splitting, that make the move of water into the deeper inside of wood, resulting in the internal decay (Amburgey and Ragon, 2008). Therefore, If the deep checks do not occur or if preservative ingredients such as mobile copper can adequately protect the exposed surfaces, the service life of the wood will increase.

The specification of the penetration depth of treated woods varies depending on species and size (AWPA, 2012a; CSA, 2015). American Wood Protection Association (AWPA) and Canadian Standard Association (CSA) require $5 \mathrm{~mm}$ penetration depths for some of the refractory species in some cases. Currently, there are no specifications for the use of the treated wood made of refractory species in Korea. Thus, it is very important to find the proper conditions of the use of refractory species suitable for domestic use. The objective of this research is to find efficient ways minimizing the decay of wood in the wooden decks fabricated using refractory species by a case study and to evaluate the degree of the contamination of copper depleted from the deck.

\section{MATERIALS and METHODS}

\subsection{Determination of wood decay index}

Jinju climate data for 2009 to 2018 were downloaded from the website of the Korean Meteorological Administration (KMA). The Scheffer index was calculated by using the following formula. The calculation used the mean number of days in the month with precipitation of $0.30 \mathrm{~mm}$, instead of $0.25 \mathrm{~mm}$ because this was the threshold used for the domestic data.

$$
\text { Scheffer climate index }=\sum_{J a n}^{D e c}\left[\frac{(\mathrm{T}-2)(\mathrm{D}-3)}{16.7}\right]
$$

where $\mathrm{T}$ is mean monthly average temperature (expressed in ${ }^{\circ} \mathrm{C}$ ), $\mathrm{D}$ is the mean number of days per month with $0.30 \mathrm{~mm}$ or more of precipitation, (T-2) $\equiv 0$ if $\mathrm{T} \leq 2$, and $(\mathrm{D}-3) 0$ if $\mathrm{D} \leq 2$.

\subsection{Selection and inspection of wooden deck}

A 10-year-old ACQ-treated European Redwood (Pinus sylvestris) deck in Jinju was chosen because it was fabricated using the treated refractory species without incising. The scheme of the deck is shown in Fig. 1.

In 2019, the deck was visually assessed for decay. Ten samples were taken from the rails and the posts. The penetration and retention were measured according to AWPA methods (AWPA, 2012b; AWPA, 2012c; AWPA, 2012d). The wood surfaces, checks, and end grain were gently probed with a metal spatula for signs of softening or cavities. The areas of high moisture content, discoloration, and collapse visible on the surface were investigated with particular attention. Table 1 shows the decay rating method in the AWPA system (AWPA, 2012e).

\subsection{Measurement of copper in soil}

The amount of copper depleted into the soil were measured in situ using a handheld XRF analyzer (DELTA handheld XRF, Olympus). The copper was measured $5,10,15,20,30,40$, and 50 from the decking boards. 


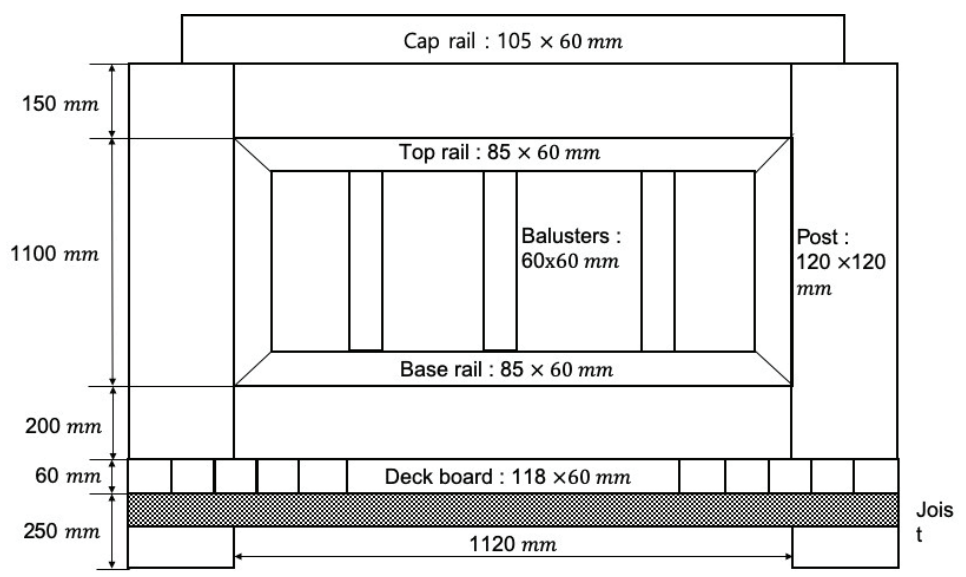

Fig. 1. The structure of the wooden deck.

Table 1. Decay rating scheme in AWPA standard E25-08

\begin{tabular}{|c|c|}
\hline Decay Rating & Condition of the board \\
\hline 10 & Sound: No evidence of decay. \\
\hline 9.5 & Trace or suspicion of attack. \\
\hline 9 & $\begin{array}{l}\text { Minor softening on end-grain or on sides of checks, or up to } 3 \% \text { of any-given cross-section } \\
\text { decayed. }\end{array}$ \\
\hline 8 & $\begin{array}{l}\text { Small pockets of decay on end-train or on sides of checks, or up to } 10 \% \text { of any given cross } \\
\text { section decayed. }\end{array}$ \\
\hline 7 & $\begin{array}{l}\text { Moderate decay or sample has between } 10-30 \% \text { of any given cross section decayed. Presence } \\
\text { of a fruitbody is an automatic rating of no higher than } 7 \text {. }\end{array}$ \\
\hline 6 & Severe decay. Sample has between $30-50 \%$ of any given cross section decayed. \\
\hline 4 & $\begin{array}{l}\text { Very severe decay with greater than } 50 \% \text { of a cross-section affected, likely to seriously affect } \\
\text { load-bearing capacity but not broken when stressed as described below. }\end{array}$ \\
\hline 0 & $\begin{array}{l}\text { Failure when stepped on sharply by a person of moderate weight }(60-80 \mathrm{~kg}) \text {. This could be } \\
\text { breakage of the board or severe surface collapse, or an inspection tool can pass totally through } \\
\text { the board. }\end{array}$ \\
\hline
\end{tabular}

\section{RESULTS and DISCUSSION}

Jinju was considered as a moderate decay zone according to Scheffer index (Kim et al., 2011; Kim and Ra, 2013; Kim and Ra, 2014). The Scheffer index of Jinju determined in 10 years is shown in Table 2. The index values are in the range between 35 and 70 , meaning that it could be considered a moderate decay zone. The average value is 58.2 , and the highest and lowest values were 69.6 in 2014 and 45.3 in 2017 . Average annual rainfall and temperature are $1558 \mathrm{~mm}$ and 13.3 .

The deck was exposed to heat, cold, ice, water, wind, and UV exposure with no periodic treatment with oil stain. The deck boards and the railings showed decay, checks, and splitting.

The other members except the deck boards were still in service. However, more than $30 \%$ of the deck boards 
Jong Bum RA

Table 2. Decay hazard index values calculated from weather data for the period 2009 to 2018 in Jinju

\begin{tabular}{ccccc}
\hline Year & $\begin{array}{c}\text { Mean Annual } \\
\text { Temperature }\left({ }^{\circ} \mathrm{C}\right)\end{array}$ & $\begin{array}{c}\text { Mean Annual } \\
\text { Precipitation }(\mathrm{mm})\end{array}$ & $\begin{array}{c}\text { Mean Number of Days per Year with } \\
\text { Precipitation }(\geq 0.30 \mathrm{~mm})\end{array}$ & $\begin{array}{c}\text { Decay Hazard } \\
\text { Index }\end{array}$ \\
\hline \hline 2009 & 13.8 & 1608.9 & 85 & 52.0 \\
2010 & 13.1 & 1896.0 & 101 & 62.0 \\
2011 & 12.5 & 2026.4 & 94 & 58.7 \\
2012 & 12.7 & 1752.9 & 97 & 54.1 \\
2013 & 13.4 & 1221.4 & 87 & 46.5 \\
2014 & 13.2 & 1644.9 & 105 & 69.6 \\
2015 & 13.4 & 1319.9 & 108 & 58.9 \\
2016 & 13.8 & 1734.6 & 98 & 58.9 \\
2017 & 13.5 & 766.7 & 77 & 49.3 \\
2018 & 13.4 & 1605.4 & 59 & 50.4 \\
\hline
\end{tabular}

Table 3. The decay rating of the wooden deck in 10 years

\begin{tabular}{|c|c|c|c|c|c|}
\hline & Part & Retention $\left(\mathrm{kg} / \mathrm{m}^{3}\right)$ & $\begin{array}{l}\text { Penetration } \\
\quad(\mathrm{mm})\end{array}$ & $\begin{array}{l}\text { The existence of checking depth } \\
\text { more than } 2 \mathrm{~cm}\end{array}$ & Decay rating \\
\hline & Post & \multirow{6}{*}{$\begin{array}{cc}\text { Total: } & 0.648 \\
\text { CuO: } & 0.441 \\
\text { DDAC: } & 0.207\end{array}$} & \multirow{6}{*}{$<6$} & Yes & 9.0 \\
\hline \multirow{4}{*}{ Rail } & Cap & & & Yes & 7.0 \\
\hline & Top & & & No & 8.5 \\
\hline & Base & & & Yes & 8.0 \\
\hline & Baluster & & & No & 8.5 \\
\hline & ecking & & & Yes & 7.0 \\
\hline
\end{tabular}

were already replaced because of severe decay. The cap rails showed much more severe decay in progress than the top and the base rails. However, the posts showed only limited decay in a few and were not in danger of failing (Table 3).

The retention and penetration of the deck did not satisfy the requirements in the Korean standards for the treated wood. The average values of the penetration and retention are $6 \mathrm{~mm}$ and $0.648 \mathrm{~kg} / \mathrm{m}^{3}$, respectively, which does not satisfy the requirements of the specification and quality standard (NIFoS, 2018). It requires more than $2.6 \mathrm{~kg} / \mathrm{m}^{3}$, and $8 \mathrm{~mm}$ for the above-ground wood.

The decking board showed extreme graying from UV exposure, warping, checking, splitting, and decaying.
The deck boards seemed to be treated with oil stain once. However, the end surfaces of many deck boards were not treated sufficiently with wood preservatives, which resulted in severe decay (Fig. 2). The decay ratings of the decking in Table 3 are the values of the decking unreplaced.

The inspection of the deck rails showed that the cap rails were under severe checking, splitting, and decay (Fig. 3). However, other treated members such as posts, top rails, base rails, and balusters had only limited decay in a few members and were not in danger of falling.

Severe decay in the cap rails can be explained by the poor penetration and retention, the occurrence of deep checking or splitting, and the exposure of untreated end surface (Fig. 3). The end surface, if cut to expose 


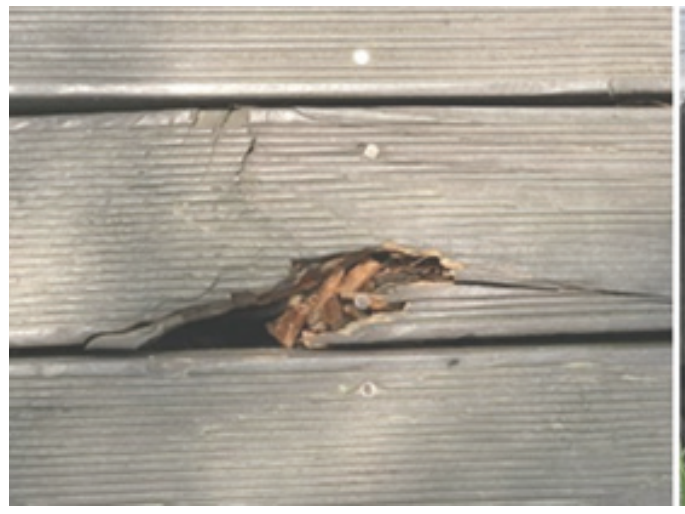

(A) Walking surface

Fig. 2. Decking boards showing severe decay.

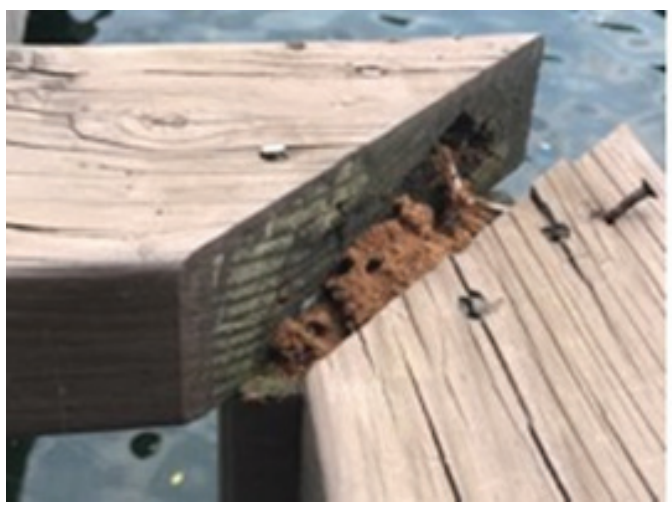

Fig. 3. The decayed parts of the cap rails.

new wood, must be treated by brush or spray application with wood preservatives. Domestically this is often overlooked, resulting in the severe decay.

To minimize the occurrence of deep checking can be a useful way to prevent the wood from decaying. The number and size of the checking that generally roles as water path were remarkably larger and bigger in the cap rails than in the top and base rails and the balusters. The phenomena may be explained by both the larger width of the cap rails and the relatively more amount of direct contact of rain and sunshine. Checks occur when the drying stresses that develop in the outer part of wood exceed the tensile strength of the wood.

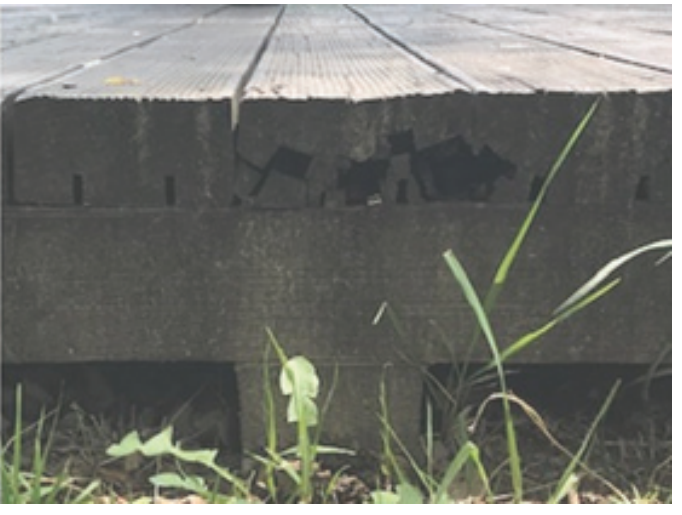

(B) End surface

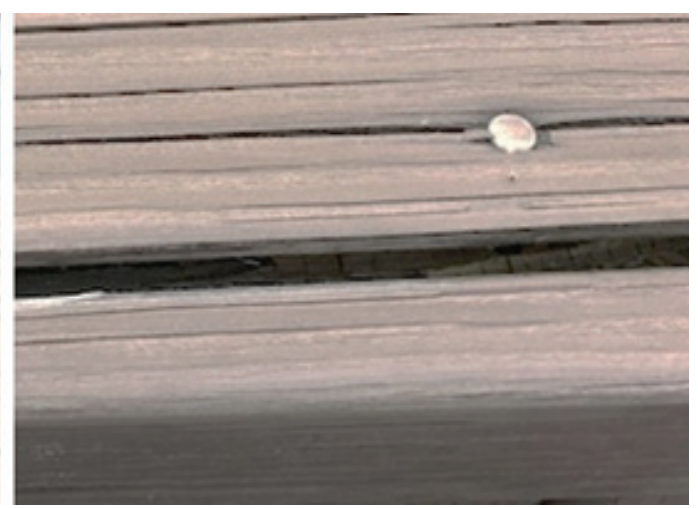

The rails that dry faster make the larger drying stresses. Deep checks accompany decay in most cases.

The poor treatability of refractory species may work as a good advantage when no deep checking occurs. If the wood is treated with wood preservatives and satisfy the penetration and retention requirements, most of the preservative ingredients exist mostly within the wood surface. Higher retention can be more efficient to prevent wood decay because some wood decay fungi have toxic thresholds higher than the retention requirements in the domestic quality standard (Freeman and Mclntyre, 2008).

However, the penetration requirements cannot 


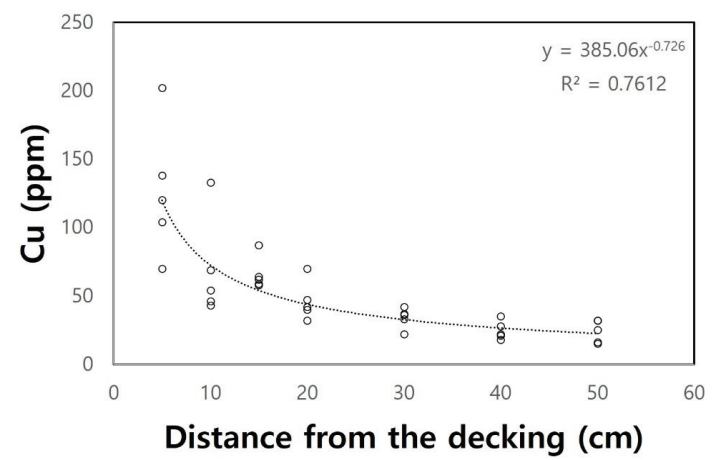

Fig. 4. The amount of copper depleted the treated wood in soil.

achieve in most of the refractory species without incising. Thus, several studies have been done to investigate the appropriate penetration depths from a practical point of view. Morris and Morrell (2014) reported that shallow penetration, less than $5 \mathrm{~mm}$, may be sufficient for nominal 2-inch material in aboveground, low-decay hazard applications where spores are the primary mode of infection if the preservative has adequate levels of mobile copper in a bio-available form.

In this research, the effect of mobile copper may not be expected because the wood did not satisfy the requirements of retention and penetration, and the thickness of the rails is over 2 inches. However, it can be said that if the occurrence of deep checking can be minimized as in the case of most of the top and base rails, and balusters, the service life of the wood can be increased.

The deck posts showed no heavy decay although the retention and penetration did not satisfy the standard. The values of decay ratings are 9, suggesting that the posts were in good conditions. Little exposure to the untreated surfaces of the posts explains this phenomenon. Many of the other parts of the deck except the post seemed to be cut after treatment, resulting in the exposure of untreated end surface.
The evaluation of the degree of copper depleted in the soil showed that the $\mathrm{Cu}$ concentration was in the range between $15 \mathrm{ppm}$ and $200 \mathrm{ppm}$ (Fig. 4).

Copper concentrations varied from $50 \mathrm{ppm}$ to 200 ppm in the soil $5 \mathrm{~cm}$ away from the deck. The copper concentration rapidly dropped to about $50 \mathrm{ppm}$ at 30 $\mathrm{cm}$. Several studies about the mobility of copper in soil showed similar results ( $\mathrm{Ra}, 2015$; Townsend, 2003). It seems that there is little concern about the environmental pollution considering that the domestic standard for copper is $150 \mathrm{ppm}$ in the residential area.

\section{CONCLUSION}

From the case study, the 10-year performance of the shell-treated wooden deck exposed in the moderate decay zone can be concluded as follows.

1. Severe decays were observed in the wooden deck, which can be explained by the failure to meet the minimum requirements for penetration and retention for treated wood.

2. Decay usually occurred in the end surface of the treated wood, which means that the end surface must be treated with wood preservatives.

3. The shell-treated wood without deep checking showed no heavy decay, suggesting that a design approach to minimize checking and splitting would be needed to increase the service life of the shell-treated wooden deck.

4. There is little concern about the environmental pollution of copper depleted from the treated wooden deck.

\section{ACKNOWLEDGMENT}

This work was supported by the Gyeongnam National University of Science and Technology Grant in 2018 . 


\section{REFERENCES}

American Wood Protection Association (AWPA). 2012a. AWPA Standard T1-12. Processing and treatment standard. AWPA, Birmingham, AL.

American Wood Protection Association (AWPA). 2012b. AWPA Standard A3-08. Standard methods for determining penetration of preservatives and fire retardants. AWPA, Birmingham, AL.

American Wood Protection Association (AWPA). 2012c. AWPA Standard A2-11. Standard methods for analysis of waterborne preservatives and fire-retardant formulations, Birmingham, AL.

American Wood Protection Association (AWPA). 2012d. AWPA Standard A17-09. Standard for determination of dedecyldimethylammonium chloride in ACQ solutions, Birmingham, AL.

American Wood Protection Association (AWPA). 2012e. AWPA Standard E25-08. Standard field test for evaluation of wood preservatives to be used above ground (UC 3B): decking method. Birmingham, AL.

Amburgey, T. L., Ragon, K. W. 2008. "Treating" treated wood-decks. Mississippi State University Southern Climatic Housing ( $\mathrm{SCH})$ Report 8

Canadian Standards Association (CSA). 2015. CSA O80 Series. Wood Preservation. CSA, Etobicoke, $\mathrm{ON}$.

Choi, Y.S., Oh, S.M., Kim, G.H. 2011. Evaluation of pretreatment moisture content and fixation characteristics of treated wood for pressure treatment of Japanese red pine and Japanese larch skin timber with ACQ, CUAZ, and CuHDO. Journal of the Korean Wood Science and Technology 39(6): 481-489.

EN 350-2. 1994. Durability of wood and wood-based products. Natural durability of solid wood. Part 2. Guide to natural durability and treatability of selected wood species of importance in Europe.

Freeman, M.H., Mclntyre, C.R. 2008. A comprehensive review of copper-based wood preservatives with a focus on new micronized or dispersed copper systems. Forest Products Journal 58(11): 6-27.

Kang, S.M., Kim, G.H., Paik, K.H. 1995. Treatment characteristics of Japanese larch heartwood with CCA or CCFZ and improving its CCA treatability by incising techniques. Journal of the Korean Wood Science and Technology 23(4): 60-66.

Kim, T., Ra, J.B., Kang, S.M., Wang, J. 2011. Determination of decay hazard index (Scheffer index) in Korea for exterior above-ground wood. Journal of the Korean Wood Science and Technology 39(6): 531-537.

Kim, T., Ra, J.B. 2013. Decay hazard (Scheffer) index values in Korea for exterior aboveground wood. Forest Products Journal 63(3-4): 91-94.

Kim, T., Ra, J.B. 2014. Change of decay hazard index (Scheffer index) for exterior aboveground wood in Korea. Journal of the Korean Wood Science and Technology 42(6): 732-739.

Morris, P.I., Morrell, J.J. 2014. Penetration and performance in western species. Proceeding, American Wood Protection Association. 110: 148-158. AWPA, Birmingham AL.

National Institute of Forest Science. 2018. The specification and quality standard of wood products, Notification No. 2018-8.

Ra, J.B. 2015. Evaluation of soil contamination by copper depleted from ACQ-treated wood. Journal of the Korean Wood Science and Technology 43(4): 504-510.

Ra, J.B., Ingram, J., Wang, J., Morris, P.I. 2017. Evaluation of preservative efficacy for refractory wood species in field tests and its implication for Korean wood preservation industry. Journal of the Korean Wood Science and Technology 47(5): 544-558.

Townsend, T., Solo-Gabriele, H., Tolaymat, T., Stook, K., Hosein, N. 2003. Chromium, copper, and arsenic concentrations in soil underneath CCA-treated wood structures. Soil \& Sediment Contamination 12(6): 779-798. 